\title{
Exploring symptom expressions according to different age groups in fibromyalgia: a cross-sectional study
}

\section{BACKGROUND}

Fibromyalgia syndrome is a chronic musculoskeletal disorder which mostly affects women. This study investigates whether the prediction of self-report based fatigue, stress, everyday memory and impact (the most affected components of health status, i.e., physical impairment, feeling good, doing work, pain, anxiety, etc.) differ between younger patients and older patients with fibromyalgia.

\section{PARTICIPANTS AND PROCEDURE}

The current study included a community-based sample of 1,205 participants who had been diagnosed with fibromyalgia according to the American College of Rheumatology criteria. Participants were categorized into four age groups (30-39, 40-49, 50-59 and 60-90). Binary logistic regression was used to analyze whether there were differences between the youngest patients (30-39) and the older patients (40-49, 50-59 and 60-90) in the prediction of each variable (i.e., fatigue, impact, stress and memory deficits).

\section{RESULTS}

When the youngest patients' scores were compared with the older patients' scores, there was at least one significant result for each dependent variable (i.e., fatigue, impact, perceived stress and everyday memory). The youngest patients reported more fatigue than the 50-59 age group and a greater impact than both the 40-49 and 50-59 age groups; furthermore, they exhibited lower everyday memory function than the 40-49 and 50-59 age groups. However, the youngest patients reported less perceived stress than the elderly patients (60-90).

\section{CONCLUSIONS}

The current findings suggest that the youngest patients generally report having more symptoms than older patients in terms of fibromyalgia. There have been a limited number of studies examining symptom expressions in different age groups. Further research should clarify the differences in expression of symptoms between age groups by investigating coping skills and illness perceptions in fibromyalgia.

KEY WORDS

perceived stress; fibromyalgia; daily life fatigue

ORGANISATION - European University of Lefke, Cyprus

AUthors' CONTRibutions - A: Study design - B: Data collection - C: Statistical analysis - D: Data interpretation .

E: Manuscript preparation · F: Literature search · G: Funds collection

CORRESPONDING AUTHOR - Buse Keskindag, European University of Lefke, Lefke, North Cyprus, via Mersin 10 Turkey,

e-mail: busekeskindag@yahoo.com

TO CITE THIS ARTICLE - Keskindag, B. (2018). Exploring symptom expressions according to different age groups

in fibromyalgia: a cross-sectional study. Health Psychology Report, 6(3), 243-251. doi: https://doi.org/10.5114/

hpr.2018.75683

RECEIVED 09.01.2018 · REVIEWED · 20.03.2018 · ACCEPTED 24.04.2018 · PUBLISHED 23.05.2018 


\section{BACKGROUND}

Fibromyalgia syndrome is a chronic musculoskeletal disorder which is poorly understood. The main syndrome symptoms are fatigue, anxiety, pain, sleep disturbance, depressive symptoms and memory deficits (Wolfe, Ross, Anderson, Russell, \& Hebert, 1995). Fibromyalgia commonly occurs among females and they usually exhibit more intense symptoms than males (Wolfe et al., 1995, 2010).

Buse Keskindag The etiology of this syndrome has not been clearly established. According to the American College of Rheumatology (ACR), fibromyalgia diagnosis requires having chronic pain for at least three months. The ACR considers fibromyalgia to be widespread pain that manifests itself on the left side of the body, the right side of the body, above the waist, below the waist and the axial skeleton (Wolfe et al., 2010).

In terms of long-term symptoms, fibromyalgia patients commonly suffer from pain, sleep disturbance, fatigue, depressive symptoms, emotional distress, intensive headaches, cognitive dysfunction, impaired memory, and anxiety (Wolfe et al., 1995). Patients usually feel sore or burning sensations, although the intensity of pain can differ among patients (Wolfe et al., 1995, 2010). Stress has been shown to be one of the major symptoms of fibromyalgia (Wolfe et al., 1995, 2010). The positive association between patients' stress levels and their symptom severity could indicate the important role of stress in symptom expression (Murray, Daniels, \& Murray, 2006). Furthermore, fibromyalgia patients have shown lower memory function than age-matched controls (Glass, Park, Minear, \& Crofford, 2005). Also, there is a high predominance of fatigue in patients with fibromyalgia (Nicassio, Moxham, Schuman, \& Gevirtz, 2002). People experiencing moderate levels of fibromyalgia can maintain normal lives; however, if symptoms are severe, the patient can feel frustrated and this can affect their lives negatively (Wolfe et al., 2010). Hence, quality of life can decrease dramatically (Wolfe et al., 2010; Murray et al., 2006).

There is limited evidence showing how fibromyalgia symptoms change as the patients get older. The National Fibromyalgia Association conducted an online-based research study with a large sample $(N=2595)$, which had a mean age of 47 . According to the results, the most prevalent symptoms were lower back pain (63\%), headaches (47\%), muscle spasms $(46 \%)$, fatigue (40\%), depression $(40 \%)$ and poor physical function (62\%) (Shillam, Jones \& Miller, 2011). Due to aging, older patients with fibromyalgia may have more intense symptoms (Valderas, Starfield, Sibbald, Salisbury, \& Roland, 2009). However, the literature presents contradictory findings. A study established that a middle-aged sample had more intense pain, depression and sleep dysfunction (Shillam et al., 2011), whereas another study reported older-aged patients as having greater symptom severity in comparison with middle-aged patients (Valderas et al., 2009). Older patients have been shown to be more effective than younger patients at coping with fibromyalgia symptoms (Shillam et al., 2011; Lee et al., 2010).

Research generally indicates that younger patients tend to report more intense symptoms across different mental and physical conditions. A study conducted among 1,782 patients with acute coronary heart disease reported that younger patients were more likely to complain of arm pain, sweating and nausea than older patients (Goldberg et al., 2000). Another study investigating age-related differences in symptoms among 1,000 patients with advanced cancer indicated that younger patients had greater pain, sleep problems, anxiety, depression, headache, nausea, constipation, vomiting (Walsh, Donnelly, \& Rybicki, 2000) and worsened general emotional wellbeing (Jordhoy et al., 2001). Similarly, a study conducted among 1,358 patients with metastatic cancer reported age differences in symptom intensity. Younger patients demonstrated more intense pain, depression and anxiety, as well as poorer general wellbeing (Cheung, Le, Gagliese, \& Zimmermann, 2011) and also more hopelessness in response to chemotherapy (Gil \& Gilbar, 2001) than did older patients. Moreover, a study examining patients with major depression demonstrated that there were age differences in symptom expression between younger and older patients. Generally the younger patients had more symptoms than the older patients. The younger patients were more likely to report death and suicide related thoughts, whereas the older patients were less likely to feel fearful, worthless, bothered and anxious although they had more mobility limitations (Hybels, Landerman, \& Blazer, 2012).

As in other health conditions, there may be age differences in symptom expressions in fibromyalgia. Also, considering that there is a disagreement among previous findings, more studies are needed to determine the age differences in symptom expressions of different age groups in fibromyalgia. More information related to age differences in symptom expression in fibromyalgia may be used to familiarize health care professionals with possible differences of symptom expression in fibromyalgia. This may contribute to management of the syndrome, the counselling process and evaluation of cases. The purpose of this study, therefore, is to investigate whether the prediction of fatigue, stress, everyday memory and impact differ when the youngest patients are compared with older patients. 


\section{PARTICIPANTS AND PROCEDURE}

\section{PARTICIPANTS}

Individuals who were older than 18 years were eligible to participate in the study. The current study included 1,205 participants who had been diagnosed with fibromyalgia syndrome based on the ACR classification criteria (Wolfe et al., 2010). The participants' ages varied in the range of 19 to 90 . Since the participants who were 19 to 29 years old consisted of a very small group $(n=58)$ within the sample, they were excluded from the study. Fibromyalgia is a chronic condition, which can affect an individual at every stage of life (Wolfe et al., 1995, 2010). Considering that the sample size is large, the participants were divided into four groups according to their age (30-39, 40-49, 50-59 and 60-90). The main reason for using these age groups was to reflect any possible differences in symptom expression at each stage in life, by comparing the youngest age group with the older groups. Some studies have investigated fibromyalgia symptoms among middle and older age groups in fibromyalgia (Shillam et al., 2011; Valderas et al., 2009; Lee et al., 2010). The current study aimed to determine possible differences in symptoms expressions between youngest patients and older patients with fibromyalgia.

\section{PROCEDURE}

The data of this study were obtained from a previous research study (Kantermann, Theadom, Roenneberg, \& Cropley, 2012). The original study was conducted to understand how fibromyalgia patients cope with the syndrome in everyday life and individual circadian phase of entrainment (i.e. chronotype). In the original study, participants completed various questionnaires. These included the Fatigue Severity Scale - FSS (Krupp, LaRocca, Muir-Nash, \& Steinberg, 1989), Perceived Stress Scale - PSS (Cohen, Kamarck, \& Mermelstein, 1983), Everyday Memory Questionnaire - EMQ, "memory failures in everyday life" (Royle \& Lincoln, 2008), Fibromyalgia Impact Questionnaire - FIQ (Burckhardt, Clark, \& Bennett, 1991), Hospital Anxiety and Depression Scale - HADS (Zigmond \& Snaith, 1983), Epworth Sleepiness Scale - ESS (Johns, 1991), and the Munich ChronoType Questionnaire - MCTQ (Roenneberg, Wirz-Justice, \& Merrow, 2003). The previous study was ethically approved by the Ethical Committee of the University of Surrey. Individuals were invited to participate in the study through advertisements announced by the Fibromyalgia Association (FMA UK). Participants were asked to complete an online-based survey in their own time. The data were collected be- tween 2010 and 2011 in the United Kingdom. Before completing the survey, participants were informed that their answers would be kept securely. An information sheet was sent, which provided information about the research. Additionally, a debriefing form including the contact details of the researchers was sent for questions related to the study.

\section{MEASURES}

The Fatigue Severity Scale (FSS) was used to assess fatigue. It involves 9 items examining physical and mental fatigue items (Krupp et al., 1989). Items are rated according to a seven-point rating scale (1 - strongly disagree, 7 - strongly agree). These items display how individuals have felt over the previous week.

Perceived stress was assessed by the Perceived Stress Scale (PSS). This five-point rating $(0-$ never, 4 - very often) scale involves 10 questions considering the frequency of stressful events, the control of stress and the ability to cope as a response to stress. The answers reflect perceived stress over the previous month. High scores represent a high level of perceived stress (Cohen et al., 1983).

The Everyday Memory Questionnaire (EMQ) was used to evaluate memory failures in everyday life. This five-point rating scale $(0$ - once or less in the last month, 4 - once or more in a day) has 13 items and it displays how frequently individuals experience memory failures (Royle \& Lincoln, 2008).

The Fibromyalgia Impact Questionnaire (FIQ) (Burckhardt et al., 1991) was used to assess how the general health status is affected by fibromyalgia over the previous week. The first item has 11 questions assessing general physical impairments and their effect on everyday life (4 point scale: 0 - always, 3 - never). The second and third items ask about how many days the patient felt good and how many days the patient missed work related to general well-being (scores range from 0 to 7). For items 4 to 10, scores range from 0 to 10 . These items assess general symptoms such as pain, fatigue, morning tiredness, stiffness, depression and anxiety. Higher scores illustrate a higher level of impact.

\section{DATA ANALYSIS}

Frequencies were checked in order to determine the age groups of the participants. After determining four age groups (30-39, 40-49, 50-59 and 60-90), the youngest age group (30-39) was chosen as the reference group for the analyses. SPSS version 19.0 was used to analyze the data. Each dependent variable (i.e., fatigue, perceived stress, everyday memory and impact) was dichotomized as high scores and
Exploring symptom expressions in fibromyalgia 
low scores based on the results. Binary logistic regressions were performed to assess whether changes in the dependent variables (i.e., fatigue, perceived stress, everyday memory and impact) can be predicted by comparing the youngest age group with the other age groups. In each binary logistic regression, the youngest age group and another age group were considered as independent variables. This process was repeated for each dependent variable (i.e., fatigue, perceived stress, everyday memory and impact). In total, 12 binary logistic regressions were conducted.

\section{RESULTS}

The participants were predominantly female (92.30\%). For each dependent variable (i.e., fatigue, everyday memory, perceived stress and impact), the youngest age group (30-39) and each of the 40-49, 50-59 and 60-90 age groups were compared separately.

\section{FATIGUE}

As is shown in Table 1, the odds ratio indicated that when the youngest age group (30-39) was compared with the 50-59 age group, for every unit in the youngest age group, we would predict a 1.734 times increase in the high level of fatigue scores. The change in the high level of fatigue scores was greater for the youngest age group (30-39) than it was for the 50-59 age group. However, when the youngest age group was compared with the other age groups (40-49 and 60-90) separately, no significant differences were found predicting a high level of fatigue.

\section{IMPACT}

The odds ratios in Table 2 demonstrate that when the youngest age group (30-39) was compared with the 40-49 age group, for every unit in the youngest age group (30-39), we would predict a 1.373 times increase in the high level of impact scores. Similar-

Table 1

Predicting high levels of fatigue by comparing the youngest age group with other groups

\begin{tabular}{|c|c|c|c|c|c|c|c|}
\hline \multirow{2}{*}{$\begin{array}{l}\text { High level } \\
\text { of fatigue }\end{array}$} & \multirow[t]{2}{*}{$N$} & \multirow{2}{*}{$\begin{array}{l}\text { Crude } \\
\text { OR }(B)\end{array}$} & \multirow[t]{2}{*}{$S E$} & \multirow[t]{2}{*}{$p$} & \multirow{2}{*}{$\begin{array}{l}\text { Adjusted OR } \\
\quad(95 \% \mathrm{Cl})\end{array}$} & \multicolumn{2}{|c|}{ Adjusted OR $(95 \% \mathrm{CI})$} \\
\hline & & & & & & Lower & Upper \\
\hline Age $30-39$ & 199 & & & $<.001$ & & & \\
\hline $\begin{array}{l}\text { Age } 30-39 \\
\text { vs. } 40-49\end{array}$ & $199-435$ & 0.07 & 0.12 & .544 & 1.08 & 0.85 & 1.36 \\
\hline $\begin{array}{l}\text { Age } 30-39 \\
\text { vs. } 50-59\end{array}$ & $199-343$ & 0.55 & 0.13 & $<.001$ & 1.73 & 1.35 & 2.22 \\
\hline $\begin{array}{l}\text { Age } 30-39 \\
\text { vs. } 60-90\end{array}$ & 199-141 & -0.27 & 0.17 & .110 & 0.76 & 0.55 & 1.06 \\
\hline Constant & & -0.13 & 0.08 & .108 & 0.88 & & \\
\hline
\end{tabular}

Note. OR - odds ratio, $\mathrm{Cl}$ - confidence interval.

Table 2

Predicting high level of impact by comparing youngest age group with other groups

\begin{tabular}{|c|c|c|c|c|c|c|c|}
\hline \multirow{2}{*}{$\begin{array}{l}\text { High level } \\
\text { of impact }\end{array}$} & \multirow[t]{2}{*}{$N$} & \multirow{2}{*}{$\begin{array}{l}\text { Crude } \\
\text { OR }(B)\end{array}$} & \multirow[t]{2}{*}{$S E$} & \multirow[t]{2}{*}{$p$} & \multirow{2}{*}{$\begin{array}{l}\text { Adjusted OR } \\
\qquad(95 \% \mathrm{Cl})\end{array}$} & \multicolumn{2}{|c|}{ Adjusted OR $(95 \% \mathrm{Cl}$} \\
\hline & & & & & & Lower & Upper \\
\hline Age $30-39$ & 199 & & & .004 & & & \\
\hline $\begin{array}{l}\text { Age } 30-39 \\
\text { vs. } 40-49\end{array}$ & $199-435$ & 0.32 & 0.12 & .007 & 1.37 & 1.09 & 1.73 \\
\hline $\begin{array}{l}\text { Age } 30-39 \\
\text { vs. } 50-59\end{array}$ & 199-343 & 0.25 & 0.12 & .038 & 1.29 & 1.02 & 1.64 \\
\hline $\begin{array}{l}\text { Age } 30-39 \\
\text { vs. } 60-90\end{array}$ & 199-141 & -0.24 & 0.16 & .147 & 0.79 & 0.57 & 1.09 \\
\hline Constant & & -0.10 & 0.08 & .203 & 0.90 & & \\
\hline
\end{tabular}

Note. OR - odds ratio, $\mathrm{Cl}$ - confidence interval. 
ly, when the youngest age group (30-39) was compared with the 50-59 age group, for every unit in the youngest age group (30-39), we would predict a 1.289 times increase in the high level of impact scores. The change in the high level of impact scores was greater for the youngest group (30-39) in comparison with the 40-49 and 50-59 age groups. Nevertheless, the level of impact did not differ significantly between the youngest (30-39) and the oldest age group (60-90).

\section{PERCEIVED STRESS}

As shown in Table 3, when the youngest and oldest age groups were compared, for every unit in the youngest age group (30-39), we would predict a 0.799 times decrease in the high level of perceived stress scores. In other words, the change in the high level of perceived stress scores was greater for the oldest age group (60-90) than the youngest age group (30-39). Also, when the youngest group (30-39) was com- pared with the other age groups (40-49 and 50-59), no significant differences were found predicting a high level of perceived stress.

\section{EVERYDAY MEMORY}

The odds ratios indicated that the change in the low level of everyday memory scores was greater for the youngest age group (30-39) than the 40-49 and 50-59 age groups. For every unit in the youngest age group (30-39), we would predict a 1.750 times increase in the low level of everyday memory scores in comparison with the 40-49 age group. Also, for every unit in the youngest age group (30-39), we would predict a 1.500 times increase in the low level of everyday memory in comparison with the 50-59 age group. However, the change in low level of everyday memory was greater in the 60-90 age group than the youngest age group (30-39) (Table 4).

\section{Table 3}

Predicting high level of perceived stress by comparing youngest age group with other groups

\begin{tabular}{|c|c|c|c|c|c|c|c|}
\hline \multirow{2}{*}{$\begin{array}{l}\text { High level of } \\
\text { perceived stress }\end{array}$} & \multirow[t]{2}{*}{$N$} & \multirow{2}{*}{$\begin{array}{l}\text { Crude } \\
\text { OR }(B)\end{array}$} & \multirow[t]{2}{*}{$S E$} & \multirow[t]{2}{*}{$p$} & \multirow{2}{*}{$\begin{array}{l}\text { Adjusted OR } \\
\quad(95 \% \mathrm{Cl})\end{array}$} & \multicolumn{2}{|c|}{ Adjusted OR $(95 \% \mathrm{Cl})$} \\
\hline & & & & & & Lower & Upper \\
\hline Age $30-39$ & 199 & & & $<.001$ & & & \\
\hline $\begin{array}{l}\text { Age } 30-39 \\
\text { vs. } 40-49\end{array}$ & $199-435$ & 0.20 & 0.11 & .066 & 1.22 & 0.99 & 1.52 \\
\hline $\begin{array}{l}\text { Age } 30-39 \\
\text { vs. } 50-59\end{array}$ & $199-343$ & 0.22 & 0.12 & .060 & 1.25 & 0.99 & 1.58 \\
\hline $\begin{array}{l}\text { Age } 30-39 \\
\text { vs. } 60-90\end{array}$ & $199-141$ & -0.80 & 0.17 & $<.001$ & 0.45 & 0.33 & 0.62 \\
\hline Constant & & -0.02 & 0.08 & .810 & 0.98 & & \\
\hline
\end{tabular}

Note. OR - odds ratio, $\mathrm{Cl}$ - confidence interval.

Table 4

Predicting low level of everyday memory by comparing youngest age group with other groups

\begin{tabular}{|c|c|c|c|c|c|c|c|}
\hline \multirow{2}{*}{$\begin{array}{l}\text { Low level } \\
\text { of everyday } \\
\text { memory }\end{array}$} & \multirow[t]{2}{*}{$N$} & \multirow{2}{*}{$\begin{array}{l}\text { Crude } \\
\text { OR }(B)\end{array}$} & \multirow[t]{2}{*}{$S E$} & \multirow[t]{2}{*}{$p$} & \multirow{2}{*}{$\begin{array}{l}\text { Adjusted OR } \\
\quad(95 \% \mathrm{Cl})\end{array}$} & \multicolumn{2}{|c|}{ Adjusted OR $(95 \% \mathrm{Cl})$} \\
\hline & & & & & & Lower & Upper \\
\hline Age $30-39$ & 199 & & & $<.001$ & & & \\
\hline $\begin{array}{l}\text { Age } 30-39 \\
\text { vs. } 40-49\end{array}$ & $199-435$ & 0.56 & 0.12 & $<.001$ & 1.75 & 1.38 & 2.22 \\
\hline $\begin{array}{l}\text { Age } 30-39 \\
\text { vs. } 50-59\end{array}$ & $199-343$ & 0.41 & 0.13 & .001 & 1.50 & 1.17 & 1.92 \\
\hline $\begin{array}{l}\text { Age } 30-39 \\
\text { vs. } 60-90\end{array}$ & $199-141$ & -1.21 & 0.19 & $<.001$ & 0.29 & 0.20 & 0.43 \\
\hline Constant & & -1.86 & 0.87 & .033 & 0.83 & & \\
\hline
\end{tabular}

Note. OR - odds ratio, $\mathrm{Cl}$ - confidence interval. 


\section{DISCUSSION}

This cross-sectional survey study aimed to explore whether symptom expression differs when the youngest patients are compared with older patients in fibromyalgia. The current study investigated fatigue, everyday memory, stress and impact in patients with fibromyalgia. The findings reveal that there was at least one significant result showing predictive differences in symptom expressions (i.e., fatigue, evBuse Keskindag memory, perceived stress and impact) when the youngest age group was compared with the older age groups. More specifically, the youngest patients (30-39) had lower memory function than the 40-59 age groups and a higher level of fatigue than those aged 50-59 years. Also, the youngest patients (30-39) reported a higher level of impact than those aged 40-59 years. However, when compared with the youngest patients (30-39), elderly patients (60-90) reported a lower level of everyday memory function and a higher level of perceived stress.

There is little information about symptom expression of different age groups in fibromyalgia. Related research in the literature present contradictory findings. In the current study, the elderly patients $(60-90)$ showed a higher level of perceived stress and lower memory function than the youngest patients (30-39). Samples of chronic pain patients have established that comorbidity is a factor affecting mood (Moss, Lawton, \& Glicksman, 1991; Parmelee, Katz, \& Lawton, 1991), memory (Valderas et al., 2009) as well as disability (Farrell, Gibson, \& Helme, 1995; Rutledge, Jones, \& Jones, 2007). However, the current results generally showed that the youngest patients reported more symptoms than the older patients. For instance, the youngest patients had higher levels of fatigue and impact and also lower memory function than middle-aged patients. There is evidence indicating younger patients to be more symptomatic than older patients (Corran, Farrell, Helme, \& Gibson, 1997; Shillam et al., 2011). Older patients suffering from chronic pain may report fewer complaints about their symptoms than younger patients (Mechanic \& Angel, 1987; Yunus, Holt, Masi, \& Aldag, 1988; Corran et al., 1997; Wright et al., 1998; Cronan, Serber, Walen, \& Jaffe, 2002). The current findings are generally supported by the previous evidence demonstrating that younger patients are more symptomatic than older patients (Yunus et al., 1988; Corran et al., 1997; Cronan et al., 2002; Shillam et al., 2011). These results may indicate that middle-aged patients experience a milder syndrome or are inclined to report fewer symptoms (Cronan et al., 2002). Considering that the youngest patients (30-39) may be inexperienced in adapting to the syndrome (Lee et al., 2010), they may report the symptoms to be more intense than the actual level.
The significant differences in symptom expressions between younger and older patients may be a result of experience with the symptom management, efficient coping skills, lifestyle changes, expectations, attributions, chronic pain-related cognitive process and interactions of certain fibromyalgia symptoms in different age groups (Corran et al., 1997; Shillam et al., 2011; Lee et al., 2010). Newly diagnosed younger patients with fibromyalgia usually develop various symptoms in the first years after the diagnosis (White, Nielson, Harth, Ostbye, \& Speechley, 2002; Liedberg, Burckhardt, \& Henriksson, 2006). Some patients may attempt to solve these problems by making minor changes in their lives, such as reduced working hours and improved medical treatment (Shillam et al., 2011). However, sometimes individuals who suffer from a chronic condition may need to make bigger changes. These changes may be more manageable for older individuals in comparison with younger individuals. Considering that younger individuals usually face more responsibilities such as family and career (Hooker, 1999), different social roles of different age groups may influence the adaptation to a health condition. Younger patients may consider their chronic condition as an additional burden (Piazza, Charles, \& Almeida, 2007).

Although fibromyalgia patients tend to adapt to their syndrome-related roles, their adaptation may vary because of individual and environmental factors (Henriksson \& Burckhardt, 1996). Better coping strategies and illness-related control may generate optimistic perceptions of health status (Cronan et al., 2002). Prior studies have noted that older individuals are more effective at coping with their symptoms by formulating more mature and problem-focused coping strategies than younger individuals (McCrae, 1982; Keefe \& Williams, 1990; Martin, Freedman, Schoeni, \& Andreski, 2010; Crimmins \& Beltran-Sanchez, 2011). A study examining age differences in emotion regulation strategies found that rumination declines with increasing age (Nolen-Hoeksema \& Aldao, 2011). In health-related domains, older adults tend to prefer more positive interpretations (Löckenhoff, \& Carstensen, 2004). Compared with younger adults, older adults indicated less negative appraisals of their cancer diagnosis (Hart \& Charles, 2013). Also, an epidemiological study analysing depressive symptoms in community based samples established that older individuals were less likely to report dysphoria/ anhedonia after controlling for differences in overall depressive symptoms, gender, minority status, educational background, marital status and employment status (Gallo, Anthony \& Muthen, 1994).

Older adults with fibromyalgia are perceived to be less negative regarding their later lives (Fleeson \& Heckhausen, 1997), since they tend to attribute their fibromyalgia symptoms to the aging process (Cronan et al., 2002). When expectations are low, in- 
dividuals will be less inclined to perceive life events and illness symptoms negatively. Although older patients may have more anomalies (Young, 1997), they may perceive their health status in a positive way by generally reporting better health than younger patients (Cockerham, Sharp, \& Wilcox, 1983). On the other hand, younger individuals tend to perceive the syndrome as a disruptive and serious condition, since they do not expect to experience pain or other symptoms (Turk, Okifuji, \& Scarff, 1995; Cronan et al., 2002). Therefore, increasing age may not contribute to the individual's well-being, although differences in perceptions may play a significant role in symptom expressions (Cronan et al., 2002).

\section{LIMITATIONS}

The present study raises the possibility that younger patients may express their fibromyalgia symptoms differently than older patients. However, this study has some limitations which may affect the interpretation of the data. Firstly, the design of the study incorporating a cross-sectional survey limits causal analysis; hence, it can only indicate relationships. Also, the contribution of gender and ethnicity to the variation of symptoms is not clear. Nonetheless, the current study is a good representation of the female-male ratio in fibromyalgia $(92.30 \%)$, since the syndrome predominantly influences females (Wolfe et al., 1995). Moreover, the syndrome severity of the individuals who voluntarily participated in this study may differ from the severity in those who did not participate. Also, the current results may be influenced by comorbid conditions, since comorbidity may develop with aging in fibromyalgia (Valderas et al., 2009).

\section{CONCLUSIONS}

The purpose of the current study was to determine whether symptom expression differs between younger patients and older patients in fibromyalgia. It was found that the younger patients generally reported more symptoms than the older patients. Overall, this study strengthens the idea that younger patients may express their fibromyalgia symptoms more intensely than older patients. However, further studies need to be carried out in order to validate the age differences in symptom expressions in fibromyalgia. More comprehensive research should be undertaken to explore how symptom expression in fibromyalgia may differ with increasing age by including individual and environmental factors in the study. Further research should aim to analyze illness perceptions and coping skills of different age groups in fibromyalgia.

\section{ACKNOWLEDGMENTS}

The author gratefully acknowledges Prof. Mark Cropley for all his contributions as scientific advisor of the study.

\section{References}

Burckhardt, C. S., Clark, S. R., \& Bennett, R. M. (1991). The fibromyalgia impact questionnaire: development and validation. Journal of Rheumatology, 18, 728-733.

Cheung, W. Y., Le, L. W., Gagliese, L., \& Zimmermann, C. (2011). Age and gender differences in symptom intensity and symptom clusters among patients with metastatic cancer. Support Care Cancer, 19, 417-423. doi: 10.1007/s00520-010-0865-2

Cockerham, W. C., Sharp, K., \& Wilcox, J. A. (1983). Aging and perceived health status. Journal of Gerontology, 38, 349-355.

Cohen, S., Kamarck, T., \& Mermelstein, R. (1983). A global measure of perceived stress. Journal of Health and Social Behaviour, 24, 386-396.

Corran, T., Farrell, M., Helme, R., \& Gibson, S. (1997). The classification of patients with chronic pain: age as a contributing factor. Clinical Journal of Pain, 13, 207-214.

Crimmins, E. M., \& Beltran-Sanchez, H. (2011). Mortality and morbidity trends: is there compression of morbidity? Journal of Gerontology B Psychological Sciences and Social Sciences, 66B, 75-86. doi: 10.1093/geronb/gbq088

Cronan, T. A., Serber, E. R., Walen, H. R., \& Jaffe, M. (2002). The influence of age on fibromyalgia symptoms. Journal of Aging and Health, 14, 370-384.

Farrell, M. J., Gibson, S. J., \& Helme, R. D. (1995). The effect of medical status on the activity level of older pain clinic patients. Journal of the American Geriatrics Society, 43, 102-107.

Fleeson, W., \& Heckhausen, J. (1997). More or less of "me" in past, present, and future: perceived lifetime personality during adulthood. Psychology and Aging, 12, 125-136.

Gallo, J. J., Anthony, J. C., \& Muthen, B. O. (1994). Age differences in the symptoms of depression: a latent trait analysis. Journal of Gerontology: Psychological Sciences, 49, 251-264.

Gil, S., \& Gilbar, O. (2001). Hopelessness among cancer patients. Journal of Psychosocial Oncology, 19, 21-33.

Glass, J. M., Park, D. C., Minear, M., \& Crofford, L. J. (2005). Memory beliefs and function in fibromyalgia patients. Journal of Psychosomatic Research, 58, 263-269.

Goldberg, R., Goff, D., Cooper, L., Luepker, R., Zapka, J., Bittner, V., Osganian, S., Lessard, D., Cornell, C., Meshack, A., Mann, C., Gilliland, J.,
Exploring symptom expressions in fibromyalgia 
\& Feldman, H. (2000). Age and sex differences in presentation of symptoms among patients with acute coronary disease: the REACT trial. Coronary Artery Disease, 11, 399-407.

Hart, S. L., \& Charles, S. T. (2013). Age-related patterns in negative affect and appraisals about colorectal cancer over time. Health Psychology, 32, 302-310. doi:10.1037/a0028523

Henriksson, C., \& Burckhardt, C. (1996). Impact of fibromyalgia on everyday life: a study of women Buse Keskindag in the USA and Sweden. Disability and Rehabilitation, 18, 241-248.

Hooker, K. (1999). Possible selves in adulthood: Incorporating teleonomic relevance into studies of the self. In T. M. Hess \& F. Blanchard-Fields (Eds.), Social cognition and aging (pp. 97-122). San Diego, CA: Academic Press.

Hybels, C. F., Landerman, L. R., \& Blazer, D. G. (2012). Age differences in symptom expression in patients with major depression. International Journal of Geriatric Psychiatry, 27, 601-611. doi: 10.1002/ gps.2759

Johns, M. W. (1991). A new method for measuring daytime sleepiness: the Epworth sleepiness scale. Sleep, 14, 540-545.

Jordhoy, M. S., Fayers, P., Loge, J. H., Saltnes, T., Ahlner-Elmqvist, M., \& Kaasa, S. (2001). Quality of life in advanced cancer patients: the impact of sociodemographic and medical characteristics. British Journal of Cancer, 85, 1478-1485.

Kantermann, T., Theadom, A., Roenneberg, T., \& Cropley, M. (2012). Fibromyalgia syndrome and chronotype: late chronotypes are more affected. Journal of Biological Rhythms, 27, 176-179. doi: 10.1177/0748730411435999.

Keefe, F. J., \& Williams, D. A. (1990). A comparison of coping strategies in chronic pain patients in different age groups. Journal of Gerontology B Psychological Sciences and Social Sciences, 45, 161-165.

Krupp, L. B., LaRocca, N. G., Muir-Nash, J., \& Steinberg, A. D. (1989). The fatigue severity scale. Application to patients with multiple sclerosis and systemic lupus erythematosus. Archives of $\mathrm{Neu}$ rology, 46, 1121-1123.

Lee, D. M., Pendleton, N., Tajar, A., O’Neill, T. W., O'Connor, D. B., Bartfai, G., ... Wu, F. C. (2010). Chronic widespread pain associated with slower cognitive processing speed in middle-aged and older European men. Pain, 151, 30-36.

Liedberg, G. M., Burckhardt, C. S., \& Henriksson, C. M. (2006). Young women with fibromyalgia in the United States and Sweden: perceived difficulties during the first year after diagnosis. Disability and Rehabilitation, 28, 1177-1185.

Löckenhoff, C. E., \& Carstensen, L. L. (2004). Socioemotional selectivity theory, aging, and health: The increasingly delicate balance between regulating emotions and making tough choices. Journal of Personality, 72, 1395-1424. doi: 10.1111/j.14676494.2004.00301.x

Martin, L. G., Freedman, V. A., Schoeni, R. F., \& Andreski, P. M. (2010). Trends in disability and related chronic conditions among people ages fifty to sixty-four. Health Affairs (Millwood), 29, 725-731. doi: $10.1377 /$ hlthaff.2008.0746

McCrae, R. R. (1982). Age differences in the use of coping. Journal of Gerontology, 37, 454-460.

Mechanic, D., \& Angel, R. J. (1987). Some factors associated with the report and evaluation of back pain. Journal of Health and Social Behaviour, 28, 131-139.

Moss, M. S., Lawton, M. P., \& Glicksman, A. (1991). The role of pain in the last year of life of older persons. The Journals of Gerontology, P46, 51-57.

Murray, T. L., Daniels, M. H., \& Murray, C. E. (2006). Differentiation of self, perceived stress and symptom severity among patients with fibromyalgia syndrome. Families, Systems, \& Health, 24, 147-159.

Nicassio, P. M., Moxham, E. G., Schuman, C. E., \& Gevirtz, R. N. (2002). The contribution of pain, reported sleep quality and depressive symptoms to fatigue in fibromyalgia. Pain, 100, 271-279.

Nolen-Hoeksema, S., \& Aldao, A. (2011). Gender and age differences in emotion regulation strategies and their relationship to depressive symptoms. Personality and Individual Differences, 51, 704-708. doi: 10.1016/j.paid.2011.06.012

Parmelee, P. A., Katz, I. R., \& Lawton, M. P. (1991). The relation of pain to depression among institutionalized aged. Journal of Gerontology, 46, P15-21.

Piazza, J. R., Charles, S., \& Almeida, D. (2007). Living with chronic health conditions: age differences in affective well-being. Journal of Gerontology: Psychological Sciences, 62B, 313-321.

Roenneberg, T., Wirz-Justice, A., \& Merrow, M. (2003). Life between clocks: daily temporal patterns of human chronotypes. Journal of Biological Rhythms, 18, 80-90.

Royle, J., \& Lincoln, N. B. (2008). The Everyday Memory Questionnaire-revised: development of a 13item scale. Disability \& Rehabilitation, 30, 114-121.

Rutledge, D., Jones, K., \& Jones, J. (2007). Predicting high physical function in people with fibromyalgia. Journal of Nursing Scholarship, 39, 319-324.

Shillam, C., Jones, K. D., \& Miller, L. (2011). Fibromyalgia symptoms, physical function and comorbidity in middle-aged and older adults. Nursing Research, 60, 309-317.

Turk, D. C., Okifuji, A., \& Scarff, L. (1995). Chronic pain and depression: role of perceived impact and perceived control in different age cohorts. Pain, 61, 93-101.

Valderas, J. M., Starfield, B., Sibbald, B., Salisbury, C., \& Roland, M. (2009). Defining comorbidity: Implications for understanding health and health services. Annals of Family Medicine, 7, 357-363. 
Walsh, D., Donnelly, S., \& Rybicki, L. (2000). The symptoms of advanced cancer: relationship to age, gender, and performance status in 1,000 patients. Support Care Cancer, 8, 175-179. doi: $10.1007 / \mathrm{s} 005209900128$

White, K. P., Nielson, W. R., Harth, M., Ostbye, T., \& Speechley, M. (2002). Chronic widespread musculoskeletal pain with or without fibromyalgia: psychological distress in a representative community adult sample. Journal of Rheumatology, 29, 588-594.

Wolfe, F., Clauw, D., Fitzcharles, M. A., Goldenberg, D. L., Katz, R. S., Mease, P., ... Yunus, M. B. (2010). The American College of Rheumatology Preliminary Diagnostic criteria for fibromyalgia and measurement of symptom severity. Arthritis \& Rheumatology, 62, 600-610.

Wolfe, F., Ross, K., Anderson, J., Russell, I. J., \& Hebert, L. (1995). The prevalence and characteristics of fibromyalgia in the general population. Arthritis \& Rheumatology, 38, 19-22.

Wright, G. E., Parker, J. C., Smarr, K. L., Johnson, J. C., Hewett, J. E., \& Walker, S. E. (1998). Age, depressive symptoms, and rheumatoid arthritis. Arthritis and Rheumatology, 41, 298-305.

Young, A. (1997). Aging and physiological functions. Philosophical Transactions of the Royal Society B Biological Sciences, 352, 1837-1843.

Yunus, M. B., Holt, G. S., Masi, A. T., \& Aldag, J. C. (1988). Fibromyalgia syndrome among the elderly: comparsion with younger patients. Journal of the American Geriatrics Society, 36, 987-995.

Zigmond, A. S., \& Snaith, R. P. (1983). The hospital anxiety and depression scale. Acta Psychiatrica Scandinavica, 67, 361-370. 